\title{
Antioxidant Potential of Pyrimidine Derivatives against Oxidative Stress
}

\author{
NISHA NAIR, JASEELA MAJEED*, P. K. PANDEY, RUCHI SWEETY AND RENU THAKUR \\ Department of Pharmaceutical Chemistry, ${ }^{1}$ School of Allied Health Sciences, Delhi Pharmaceutical Sciences and Research \\ University, New Delhi 110017, India
}

\section{Nair et al.: Antioxidant Potential of Pyrimidine Derivatives}

The human body is under constant attack from oxidative stress which in turn induces the excessive production of free radicals, particularly the reactive oxygen species in the body which causes damage to cells, proteins and deoxyribonucleic acid. Free radicals are associated with progression of numerous pathological disruptions in humans including cancer, inflammation, atherosclerosis, Alzheimer's disease, Parkinson's disease and aging as well. Antioxidants are the so called "free radical scavengers" of the body, with ability to reduce the risk of chronic diseases by diminishing oxidative damage. Pyrimidines are heterocyclic molecule with ability to be utilized in therapeutics as antioxidant. Recently, novel approaches have been made and significant progress has occurred in last few years to overcome damage caused by free radical generation using pyrimidine derivatives. The current review focuses on synthesizable pyrimidine derivatives that show promise towards future development as antioxidants with therapeutic purpose.

Key words: Antioxidant, pyrimidines, free radicals, oxygen scavenger, superoxides

Heterocyclic compounds have contributed to development of large number of novel drugs till now ${ }^{[1]}$. Many heterocyclic compounds exist in nature as part of structural unit of bioactive molecules like alkaloids, vitamins, hormones, haemoglobin and amino acids whereas synthetic heterocyclic compounds like pyridine $^{[2]}$, piperidines ${ }^{[3]}$, pyrimidines ${ }^{[4]}$ have shown to have significant biological activities. Pyrimidine and $\mathrm{N}$-base analogues of uracil, thymine and cytosine have a significant role in constitutional part of Deoxyribonucleic Acid (DNA) and Ribonucleic Acid (RNA) in the form of nitrogenous bases as well as several coenzymes in the body ${ }^{[5]}$. The importance of the pyrimidine and its derivative compounds may be established by the fact that many drugs contain pyrimidine nucleus ${ }^{[6]}$. As a result, several pyrimidine derivatives have gained attention due to interesting pharmacological activities such as antitumor ${ }^{[7]}$, antiviral $^{[8]}$, antioxidant ${ }^{[9]}$, anti-malaria ${ }^{[10,11]}$, antibacteria ${ }^{[12-14]}$, anti-funga ${ }^{[15,16]}$, anti-inflammatory ${ }^{[17]}$ and anti-hypertensive activity ${ }^{[18]}$.

Reactive Oxygen Species (ROS) like peroxides, superoxide and hydroxy peroxides are produced either as the metabolic by-products of oxidative metabolism as a consequence of both enzymatic and nonenzymatic reactions of different substrates like fatty acids, glucose

*Address for correspondence

E-mail: jaseelapharma2017@gmail.com

January-February 2022 and amino acids to produce energy in the body or from external sources such as exposure to X-rays, ozone, cigarette smoking, air pollutants and industrial chemicals ${ }^{[19,20]}$. Free radicals produced by oxidative metabolism may undergo a chain reaction in presence of water, which may lead to oxidative damage to the cell structures, vital biomolecules-lipids, nucleic acids and proteins and thus have deleterious effect on the body by bringing about cell damage and homeostatic disruption. ROS such as superoxide, hydrogen peroxide, hydroxyl radical and their metabolites play an important role in carcinogenesis. ROS causes crosslinking and induce DNA damage. Free radicals and other reactive species are also produced by radiolysis or by direct action of radiation on DNA; these effects cause cell mutation and cancer. Lipid peroxides are also considered responsible for carcinogenesis ${ }^{[19,20]}$.

Antioxidants are free radical scavengers which play a crucial role in prophylaxis and prevent propagation

This is an open access article distributed under the terms of the Creative Commons Attribution-NonCommercial-ShareAlike 3.0 License, which allows others to remix, tweak, and build upon the work non-commercially, as long as the author is credited and the new creations are licensed under the identical terms

Accepted 05 January 2022

Revised 02 August 2021

Received 08 June 2020 Indian J Pharm Sci 2022;84(1):14-26 
of diseases due to excessive oxidative stress in the body ${ }^{[21]}$. However, to prevent those reactions there are many protective compounds present or produced in the cell such as superoxide dismutase, catalase, glutathione peroxidase, tocopherol, ascorbic acid, glutathione and uric acid ${ }^{[22]}$. These antioxidants trap the free radicals by donating an electron to the rampant free radical and neutralize it, thus reducing its capacity to damage and prevent the irreversible adverse effects on the cells, while they may become new free radical which is less active and less dangerous ${ }^{[23]}$. They also inhibit the reaction involved in lipid peroxidation and due to this property, they have found an important place in therapy and control of several diseases like atherosclerosis, DNA damage leading to mutation and cancer, neurodegenerative disease like Alzheimer's disease, Parkinsonism and ageing process ${ }^{[24]}$. Small molecules such as vitamin $\mathrm{C}$, vitamin $\mathrm{E}$, uric acid and glutathione play an important role as intracellular antioxidants whereas synthetic antioxidants such as tert-butyl hydroxyl-toluene, Tert-Butylhydroxyanisole (TBHA) and Tert-Butylhydroquinone (TBHQ) have been widely used in the food industry to retard lipid peroxidation. However, these synthetic antioxidants are not preferred for pharmacological use due to toxicological concerns ${ }^{[25]}$. Thus, focus is shifted more on identification, synthesis and production of safe and non-toxic antioxidant for medicinal use. This review focuses on current trend in the search of non-toxic molecules, synthesisable pyrimidine derivatives that show promising potency and can serve as potential antioxidants.

\section{CLINICALLY USED ANTIOXIDANTS HAV- ING PYRIMIDINE RING}

As observed in studies, excess production of free radicals leads to many deleterious effects on the body and in order to overcome this oxidative stress the body synthesizes many free radical scavengers ${ }^{[26]}$. With progression of age, the defensive mechanism of body is unable to do so and the antioxidants have to be supplemented from outside the body. To serve this purpose, many antioxidants with pyrimidine nucleus such as riboflavin, thiamine, pyrazolopyrimidine, triazolopyrimidines have been synthesized in past years (fig. 1). In spite of the availability of many antioxidants with pyrimidine nucleus only few of them are used clinically due to their toxic effects ${ }^{[27]}$.

Riboflavin is commonly known as "B group water soluble vitamin" or specifically as B2 vitamin. Glutathione is a crucial antioxidant produced by human body but it is active only in reduced form. Riboflavin and the glutathione reductase enzyme are both used to convert oxidized glutathione to the reduced form thereby depicting antioxidant activity. Riboflavin plays an important role in maintaining the levels of other antioxidant enzymes, such as superoxide dismutase, catalase and glutathione peroxidase and also helps in the prevention and treatment of many eye disorders ${ }^{[28]}$. The clinically used riboflavin formulations available in the market are riboflavin injection, Photrexa ${ }^{\circledR}$ (eyedrop), capsules (Bacmin, Biovita), Alertonic, Active FE, B-combo, B-Plex, C-Nate DHA and Centratex.

Thiamine another B family vitamin commonly known as B1 vitamin, possess remarkable anti-oxidant activity. It has been shown to inhibit lipid peroxidation in rat liver microsomes in vivo and free radical oxidation of oleic acid in vitro. Thiamine act by transfer of $2 \mathrm{H}^{+}$from $\mathrm{NH}_{2}$ group of pyrimidine ring and $\mathrm{H}^{+}$from thiazole ring to reactive free radical species. Thiamine in turn reacts with ROS and itself gets oxidized to thiochrome and thiamine disulphide. Formulations are available which can be used in deficiency of thiamine or therapeutically
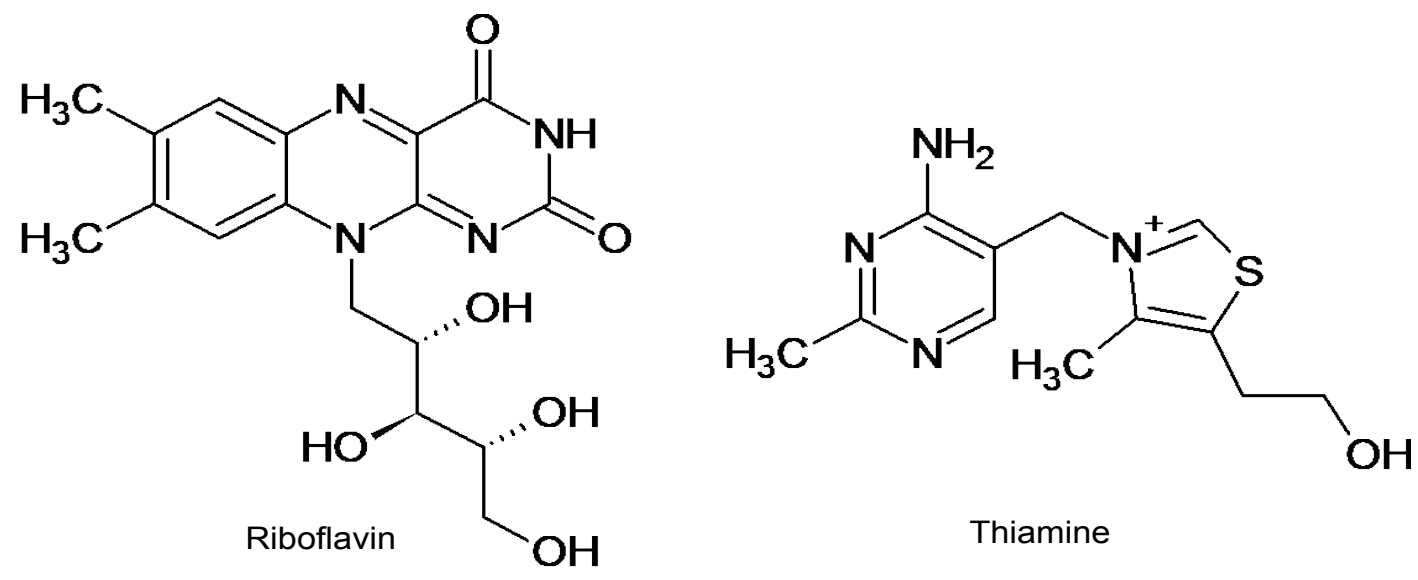

Thiamine

Fig. 1: Clinically used antioxidants with pyrimidine ring 
for the treatment of polyneuropathies and cardiovascular disease that are exaggerated by oxidative stress ${ }^{[29]}$. Some clinical formulations of thiamine used recently include benfotiamine, which is an S-acyl derivative, allithiamine, synthetic sulbutiamine, betaxin and fursultiamine (thiamintetrahydrofurfuryl disulphide). Benfotiamine being lipid insoluble formulations shows maximum bioavailability than other water soluble ones.

\section{EVALUATION OF ANTIOXIDANT ACTIVITY}

Evaluation of antioxidant activity is necessary for determining the potency of existing and newly synthesized compounds for comparing their relative activities. Numerous methods have been identified for evaluation of antioxidants based on various principles.

\section{In vitro methods:}

A single antioxidant test method is inefficient in determining the absolute activity of the compound therefore several methods are used for evaluation of antioxidant activities. 2,2-diphenyl-1-picrylhydrazyl (DPPH) method is the most commonly used in vitro method, however different methods have their own advantages and disadvantages.

DPPH method: DPPH is the simplest and widely reported method. DPPH radical scavenging test is a standard and rapid technique for screening of Radical Scavenging Activity (RSA) ${ }^{[17]}$. It measures the ability to donate hydrogen or electron to RSA for evaluation of antioxidant activity. In this method, the extent of bleaching of the purple colour of methanolic solution of DPPH is used to indicate the antioxidant activity of the test compound. The absorbance of observed colour is established under wavelength $517 \mathrm{~nm}$ using spectrophotometric method. DPPH is a stable free radical due to delocalisation of spare electron on it and do not allow its dimerization like other free radicals.

Percentage of scavenging activity $=\left[\left(\mathrm{A}_{\text {control }}-\mathrm{A}_{\text {sample }}\right) /\right.$ $\left.\mathrm{A}_{\text {blank }}\right] \times 100$

Where $\mathrm{A}_{\text {Control }}$ is the absorbance of the control reaction, $\mathrm{A}_{\text {sample }}$ is absorbance of test compound ${ }^{[30]}$.

Nitric Oxide (NO) scavenging test: In this method NO free radicals were generated from sodium nitroprusside at physiological $\mathrm{pH}$ which is then combined with oxygen to form stable compound. This NO free radical is determined quantitatively using Griess reagent ${ }^{[31]}$. The absorbance is measured by colorimetric method at
$546 \mathrm{~nm}$. The percentage inhibition of NO radicals is given by the equation:

Percentage inhibition $(\mathrm{NO}$ radical $)=\left[\mathrm{A}_{0}-\mathrm{A}_{1}\right] / \mathrm{A}_{0} \times 100$

Where $A_{0}$ is absorbance before reaction and $A_{1}$ is the absorbance measured with Griess reagent ${ }^{[32]}$.

Ferric reducing antioxidant power assay: In this method the ability of a compound to reduce ferric ion to ferrous ion at low $\mathrm{pH}$, is measured to evaluate antioxidant activity. A diode-array spectrophotometer is used to measure the absorbance at $593 \mathrm{~nm}$. During the course of reaction, colour changes from various shades of green and blue due to reduction which depends upon the reducing ability expressed as $\mathrm{mm}$ of $\mathrm{Fe}^{2+}$ equivalents per $\mathrm{kg}$ of the material. This method was developed by Benzie et al. ${ }^{[33]}$.

Hydrogen peroxide $\left(\mathrm{H}_{2} \mathrm{O}_{2}\right)$ scavenging activity: $\mathrm{H}_{2} \mathrm{O}_{2}$ is generated in the body during various metabolic processes and is rarely reactive unless it is converted to reactive hydroxyl radical $\left(\mathrm{OH}^{-}\right)$on exposure to Ultraviolet (UV) which may lead to various deleterious effects $^{[34]} \cdot \mathrm{H}_{2} \mathrm{O}_{2}$ assay is the measure of ability of the sample to scavenge $\mathrm{H}_{2} \mathrm{O}_{2}$. The hydroxyl radicals are reacted with dimethyl sulphoxide to yield formaldehyde. The released formaldehyde produces intense yellow colour with Nash reagent $(2 \mathrm{M}$ ammonium acetate with $0.05 \mathrm{M}$ acetic acid and $0.02 \mathrm{M}$ acetyl acetone in distilled water). The intensity of the colour is measured at $412 \mathrm{~nm}$ spectrophotometrically against reagent blank. Formaldehyde produces strong yellow blank reagent ${ }^{[35]}$.

Percentage scavenged $\mathrm{H}_{2} \mathrm{O}_{2}=\left[\left(\mathrm{A}_{\mathrm{i}}-\mathrm{A}_{\mathrm{t}}\right) / \mathrm{A}_{\mathrm{i}}\right] \times 100$

Where, $\mathrm{A}_{\mathrm{i}}$ is absorbance of control and $\mathrm{A}_{\mathrm{t}}$ is absorbance of test.

Total radical-trapping antioxidant parameter method: This method is based on the fact that antioxidants are involved in protection of fluorescence decay of R-phycoerythrin (R-PE) during peroxidation reaction and decrease in fluorescence of R-PE by a radical generator 2,2'-azobis(2-amidinopropane) (ABAP) is measured in the presence of antioxidant. The antioxidative activity is evaluated by measuring the decay in decolouration. According to Ghiselli et al. ${ }^{[36]}$ a diluted sample of $120 \mu 1$ is added to phosphate buffer ( $\mathrm{pH} 7.4,2.4 \mathrm{ml})$, diluted R-PE (30 $\mu 1)$, bi-distilled water $(375 \mu 1)$ and $75 \mu 1$ of ABAP; the reaction kinetics is recorded for $45 \mathrm{~min}$ by a luminescence spectrometer at $38^{\circ}$. The length of lag phase can be used to determine the total radical-trapping antioxidant parameter value produced by sample compared with standard ${ }^{[37]}$. 
Oxygen Radical Absorbance Capacity (ORAC) method: ORAC is a revolutionary new test tube analysis for estimating antioxidant power of foods and chemical substances. It is performed using b-Phycoerythrin (b-PE) or fluorescein as target molecule. Trolox is employed as a standard in this test to determine the Trolox Equivalent (TE). The ORAC value is then calculated using TE and expressed as ORAC units or value and higher the ORAC value, greater the scavenging capability against free radicals. Based on generation of free radical using 2,2-azobis(2amidinopropane) dihydrochloride (AAPH), this assay measures the decrease in fluorescence in the presence of free radical scavengers. Litescu et al. ${ }^{[38]}$ described an automated ORAC assay. In this assay b-PE was used as a target, Trolox as standard control and AAPH as a peroxy free radical generator where on addition of AAPH to the test solution, the fluorescence is recorded and the antioxidant activity is expressed as TE.

\section{In vivo methods:}

These methods consist of administration of the test compound into the testing animals in a definite dose. After a specified time, the tissues and cells from the animals are subjected to evaluation by sacrificing the animals.

Reduced glutathione method: Glutathione-SH (GSH) is a reductase enzyme present inside the cells of the body. It protects the cell structure from ROS, peroxides and other toxic compounds. Tissue homogenate is added to Ellman's reagent and the absorbance is measured at 412 nm against blank. The absorbance of test compounds is compared with standard curve of GSH. The method was developed by Owens et al. ${ }^{[39]}$.

Ferric reducing ability of plasma: This method is based on the same principle as in vitro ferric reducing power assay described in the in vitro method. It includes measurement of increase in the absorbance due to formation of ferrous ions from ferric reducing ability of plasma reagent containing 2,4,6-Tri(2-pyridyl)s-triazine (TPTZ) and Ferric Chloride Hexahydrate $\left(\mathrm{FeCl}_{2} \cdot 6 \mathrm{H}_{2} \mathrm{O}\right)$. The absorbance is measured at 593 $\mathrm{nm}^{[40]}$.

Catalase assay: Aebi method can be used to determine catalase activity in erythrocyte lysate by using a spectrophotometer. At $240 \mathrm{~nm}$, the catalase activity is measured for $1 \mathrm{~min}$ and the molar extinction coefficient of $\mathrm{H}_{2} \mathrm{O}_{2}$, which is $43.6 \mathrm{M}$ per $\mathrm{cm}$, is used to determine the activity, where 1 unit of activity is equal to $1 \mathrm{mmol}$ of $\mathrm{H}_{2} \mathrm{O}_{2}$ degraded per minute and is expressed as units per milligram of protein.

Superoxide Dismutase (SOD) method: This method is given by McCord and Fridovich. The method can be used for estimating antioxidant activity in the erythrocyte lysate which is prepared from the $5 \% \mathrm{Red}$ Blood Corpuscles (RBC) suspension by adding $50 \mu 1$ of the erythrocyte lysate to $75 \mathrm{mM}$ of Tris- $\mathrm{HCl}$ buffer $(\mathrm{pH}$ 8.2), followed by $30 \mathrm{mM}$ Ethylenediaminetetraacetic Acid (EDTA) and $2 \mathrm{mM}$ of pyrogallol and the absorbance is measured in spectrometer for $3 \mathrm{~min}$ which shows an increase in absorbance at $420 \mathrm{~nm}$. One enzyme activity exhibited $50 \%$ inhibition of the rate of autooxidation of pyrogallol as determined by change in absorbance $/ \mathrm{min}$ at $420 \mathrm{~nm}$. The activity of SOD is expressed as units per $\mathrm{mg}$ of protein ${ }^{[41]}$.

Lipid Peroxidation (LPO) assay: LPO assay is an autocatalytic process generally followed by cell death. This process may lead to peroxidative tissue damage and cause inflammation, cancer and toxicity of xenobiotics and aging. Malondialdehyde (MDA) is one of the end products in the lipid peroxidation process, which is accepted as an indicator of lipid peroxidation. In this method described by Okhawa, the tissues are homogenized in $0.1 \mathrm{M}$ buffer of $\mathrm{pH} 7.4$ with a Teflon glass homogenizer. Amounts of MDA produced primarily are used to determine the lipid peroxidation in the homogenate. Tissue homogenate of $8.1 \%$ sodium dodecyl sulphate, acetic acid and 2-thiobarbituric acid are added then heated at $95^{\circ}$. Then tubes are cooled down to room temperature and final volume made to $5 \mathrm{ml}$ in each tube. $5 \mathrm{ml}$ of butanol:pyridine (15:1). The upper organic layer is taken after centrifugation and its optical density is measured at $532 \mathrm{~nm}$ against an appropriate blank. The lipid peroxide level can be expressed in $\mathrm{n}$ moles of thiobarbituric acid reactive substances $/ \mathrm{mg}$ protein using an extinction coefficient of $1.56 \times 10^{5} \mathrm{MLcm}^{-1[19]}$.

\section{CURRENT TRENDS IN EVALUATION OF ANTIOXIDANT ACTIVITY}

DPPH method for assay gives more accurate results but there are few methods available which have other advantages and are used very often for carrying out the assay procedure of antioxidant compounds.

\section{Trolox Equivalent Antioxidant Capacity (TEAC) assay:}

TEAC method is a widely accepted method for this purpose. TEAC method provides the measure of 
relative antioxidant activity of a given substance with reference to a standard substance, Trolox ${ }^{[41]}$. Three methods for TEAC have been developed over the time. These methods may be used interchangeably which may create significant variability in the measurements of the antioxidants. The 'pre-addition technique' (employed by adding antioxidants before radical generation) for TEAC I measured the delaying ability of radical formation and scavenging property of the compound. 2,2'-azino-bis(3-ethylbenzothiazoline-6-sulfonic acid (ABTS)/TEAC method is used widely today because of its operational simplicity, reproducibility, diversity and most importantly it provides flexible use in hydrophilic and lipophilic antioxidant capacity ${ }^{[42]}$.

\section{LEAD COMPOUND AS ANTIOXIDANT TEMPLATES}

Chandrashekaraiah et al. ${ }^{[43]}$ synthesized a series of pyrimidine-azitidinone analogues. All compounds are tested for antioxidant property by DPPH, NO and $\mathrm{H}_{2} \mathrm{O}_{2}$ methods. DPPH method for assay of antioxidants measures the hydrogen donating capacity of the molecules in the sample. Compounds 1a1, 1a2 and 1a3 (fig. 2a), due to the presence of mild electron donating groups such as chloro groups attached to the rings, showed good radical scavenging activity in all three methods when compared with the standard drug ascorbic

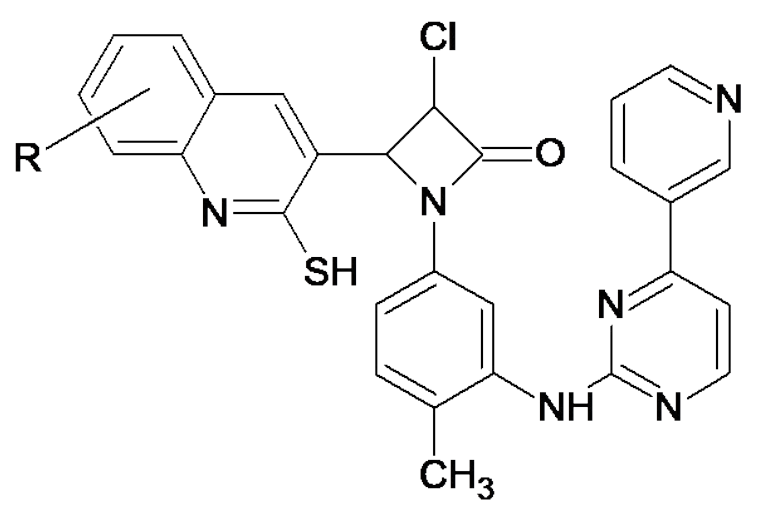

\begin{tabular}{|c|r|r|r|}
\hline & $1 \mathrm{a} 1$ & $1 \mathrm{a} 2$ & $1 \mathrm{a} 3$ \\
\hline $\mathrm{R}$ & $5-\mathrm{Cl}$ & $4-\mathrm{Cl}$ & $3-\mathrm{Cl}$ \\
\hline
\end{tabular}

(a) acid. The Half-maximal inhibitory concentration $\left(\mathrm{IC}_{50}\right)$ value of the standard ascorbic acid in DPPH method was found to be 15.15 at $25 \mu \mathrm{g} / \mathrm{ml}$, whereas the $\mathrm{IC}_{50}$ values of the compounds $1 \mathrm{a} 1,1 \mathrm{a} 2$ and $1 \mathrm{a} 3$ were found to be $17.72,17.21$ and $16.92 \mu \mathrm{g} / \mathrm{ml}$ respectively ${ }^{[43]}$.

Rangaswamy et $a l .{ }^{[44]}$ synthesized series of novel 2,4,6-substituted pyrimidine derivatives conjugated by sulfonyl chloride attached with benzofuran at C-6. All the newly synthesized compounds were evaluated for their antioxidant activity by using three in vitro assays DPPH radical scavenging activity ${ }^{[17]}, \mathrm{N}, \mathrm{N}$-dimethylp-phenylenediamine (DMPD) and ferric ion reducing power assay. Among the synthesized compounds, $1 \mathrm{~b}$ and $1 \mathrm{~b} 1$ (fig. $2 \mathrm{~b}$ ) possessed maximum radical activity as well as were more potent than the standard when 4-hydroxyphenyl substitution at S-linked C-2 and C-6 positions of pyrimidine was present as well as with 4-hydroxy-3-methoxyphenyl substitution at C-6 position of pyrimidine. $\mathrm{IC}_{50}(\mathrm{DPPH})$ values of these compounds were 08 and 10 micro molar respectively ${ }^{[4]}$.

Khoobi et al. ${ }^{[45]}$ synthesized novel series of 4H-chromenes containing a pyrimidine-2-thione. The antioxidant activities of the synthesized chromenopyrimidinethiones were evaluated by two in vitro methods (DPPH and $\mathrm{ABTS}$ ) in order to compare the results. Two controls, ascorbic acid and Trolox are included. All pyrimidinethione derivatives

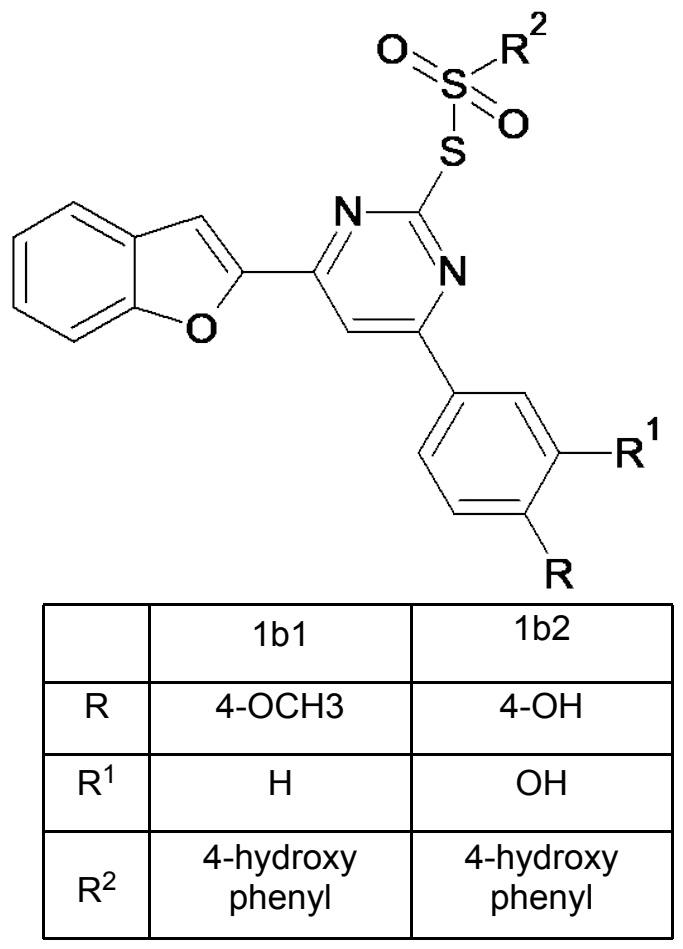

(b)

Fig. 2: (a) Compounds 1a1, 1a2 and 1a3 and (b) Compounds $1 \mathrm{~b} 1$ and $1 \mathrm{b2}$ 
exhibited significant DPPH radical scavenging activity against their precursors with $\mathrm{IC}_{50}$ values less than $42 \mu \mathrm{g} / \mathrm{ml}$. The ABTS radical cation scavenging capacity of chromenopyrimidinethiones demonstrated that all compounds have good ability to trap free radicals. The $\mathrm{IC}_{50}$ values of synthesized compounds were in the range of $21.28-72.98 \mu \mathrm{g} / \mathrm{ml}$. Among the chromenopyrimidinethiones, compound 2a (fig. 3a) exhibited the most potent antioxidant activity in both DPPH and ABTS methods. Although compounds 2a was not as potent as reference drug Trolox, but its antioxidant activity could be considered as associated property of the title compound ${ }^{[45]}$.

Kotaiah et al. ${ }^{[21]}$ synthesized a series of 1,3,4-oxadiazole tagged thieno[2,3-d]pyrimidine derivatives. All the compounds are tested for in vitro antioxidant property by $\mathrm{DPPH}$, $\mathrm{NO}$ and $\mathrm{H}_{2} \mathrm{O}_{2}$ methods respectively. Compounds 2b, 2c, 2d and 2e (fig. 3b) showed good radical scavenging activity in all three methods due to the presence of mild electron donating groups such as difluoro, fluoro and chloro-fluoro groups attached to the benzene rings when compared with the standard drug, ascorbic acid. The $\mathrm{IC}_{50}$ value of the standard ascorbic acid in DPPH method was found to be $15.11 \mathrm{mg} / \mathrm{ml}$ at $25 \mathrm{mg} / \mathrm{ml}$ whereas the $\mathrm{IC}_{50}$ values of the compounds $2 \mathrm{~b}$, $2 \mathrm{c}, 2 \mathrm{~d}$ and $2 \mathrm{e}$ were found to be $16.35,16.91,17.25$ and $17.70 \mathrm{mg} / \mathrm{ml}$ respectively ${ }^{[21]}$.

Rani et $a l .{ }^{[46]}$ synthesized new series of tetrahydroimidazo[1,2- $\alpha$ ]pyrimidine-6-carboxamide analogues. The antioxidant activity of the synthesized compounds was evaluated using free radical scavenging DPPH assay via spectrophotometer and it was demonstrated that compounds $3 \mathrm{a}$ and $3 \mathrm{~b}$ (fig. 4a) exhibited excellent activity due to the presence of electron releasing groups on benzylidene moiety. At absorbance of $517 \mathrm{~nm}$ the compounds show $\mathrm{IC}_{50}$ values of 46.31 and 48.81 respectively which compares with standard drug ascorbic acid. These compounds may be used as a lead for development of new age antioxidant ${ }^{[46]}$.

Mansouri et al. ${ }^{[47]}$ synthesized some novel Biginellitype pyrimidines which are 4-(furan-2-yl)-6-methyl2-thioxo-1,2,3,4-tetrahydropyrimidine-5-carboxylate esters. Their antioxidant potential was assessed using three different methodologies, namely DPPH free radical scavenging, reducing power and hydrogen peroxide scavenging assays and two standards, ascorbic acid and gallic acid were included. Compound $3 \mathrm{c}$ (fig. 4b) was the most potent antioxidant with the $\mathrm{IC}_{50}$ of $0.6 \mathrm{mg} / \mathrm{ml}$. The results of reducing power assays proved $3 \mathrm{~d}$ and $3 \mathrm{e}$ as the moderate reducing agents. All of the studied compounds were very weak compared with gallic acid in scavenging hydrogen peroxide ${ }^{[47]}$.

Bhalgat et al. ${ }^{[48]}$ synthesized a series of novel pyrimidines and its triazole fused derivatives. All of these synthesized compounds when screened for in vitro antioxidant activity by various methods such as scavenging of hydrogen peroxide, scavenging of nitric
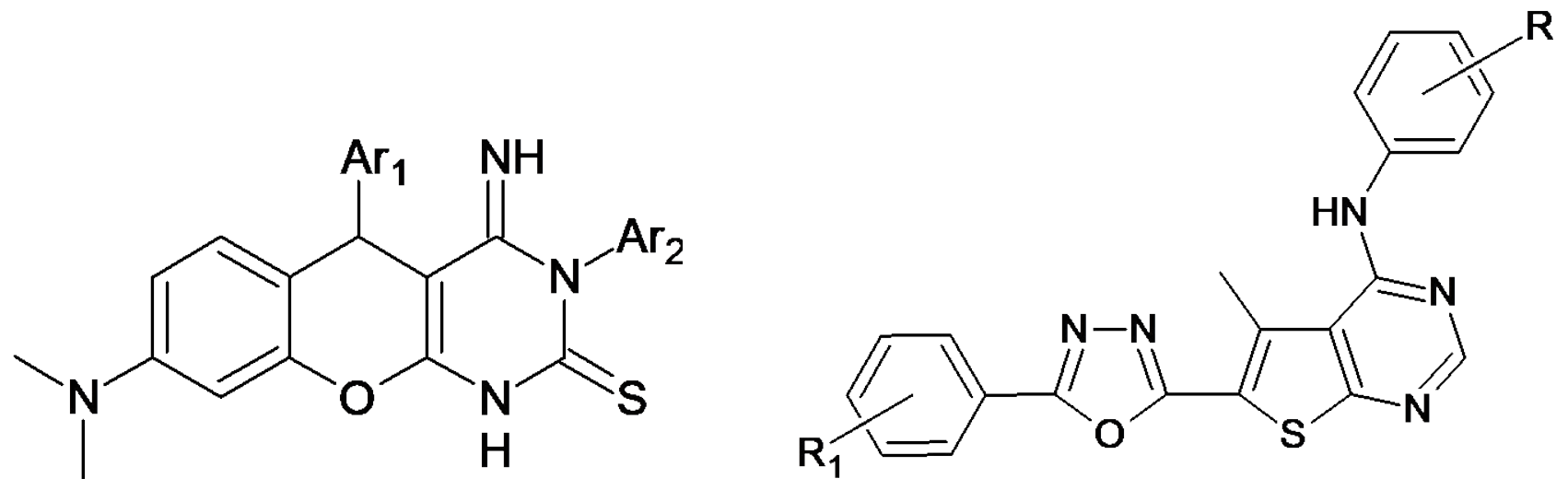

\begin{tabular}{|c|c|c|}
\hline & \multicolumn{1}{|c|}{$\mathrm{Ar}_{1}$} & $\mathrm{Ar}_{2}$ \\
\hline $2 \mathrm{a}$ & $\begin{array}{l}3,4,5 \text { trimethoxy } \\
\text { phenyl }\end{array}$ & phenyl \\
\hline
\end{tabular}

\begin{tabular}{|c|c|c|c|c|}
\hline & $2 b$ & $2 c$ & $2 d$ & $2 e$ \\
\hline$R$ & $4-F$ & $4-F$ & $2,4-d i F$ & $2,4-d i F$ \\
\hline$R_{1}$ & $4-H$ & $4-C l$ & $4-H$ & $4-C l$ \\
\hline
\end{tabular}

(a)

(b)

Fig. 3: (a) Compound 2a and (b) Compounds 2b, 2c, 2d and 2e 


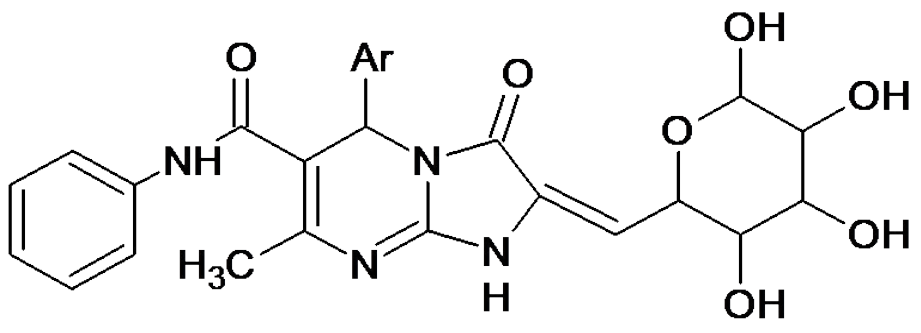

\begin{tabular}{|l|l|l|}
\hline & \multicolumn{1}{|c|}{$3 \mathrm{a}$} & \multicolumn{1}{c|}{$3 \mathrm{~b}$} \\
\hline Ar & $\begin{array}{l}3,4,5- \\
\text { trimethoxyphen } \\
\text { yl }\end{array}$ & $\begin{array}{l}4- \\
\text { methoxyphenyl }\end{array}$ \\
\hline
\end{tabular}

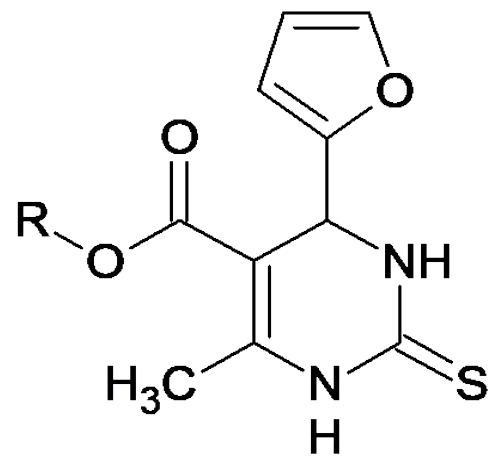

\begin{tabular}{|c|c|c|c|}
\hline & $3 c$ & $3 d$ & $3 e$ \\
\hline$R$ & iso- $_{3} \mathrm{H}_{7}$ & tert- $\mathrm{C}_{4} \mathrm{H}_{9}$ & $\mathrm{CH}_{2} \mathrm{C}_{6} \mathrm{H}_{5}$ \\
\hline
\end{tabular}

Fig. 4: (a) Compounds 3a and $3 b$ and (b) Compounds 3c, 3d and 3e

oxide radical, lipid peroxidation inhibitory activity revealed that some of the tested compounds showed moderate to good antioxidant activity. 4a has shown good antioxidant activity as compared to standard by scavenging of nitric oxide radical and scavenging of hydrogen peroxide method, while $4 \mathrm{~b}$ showed most potent antioxidant activity by scavenging of nitric oxide radical method (fig. 5) ${ }^{[48]}$.

Abu-Hashem et al. ${ }^{[49]}$ synthesized a series of thiazolopyrimidines, pyrrolothiazolopyrimidines and triazolopyrrolo-thiazolopyrimidines. The newly developed compounds were subjected for their antioxidant activity; out of the synthesized compounds, $5 \mathrm{a}$ and $5 \mathrm{~b}$ (fig. 6) manifested potent antioxidative activity in the lipid peroxidation assay. Novel thiazolopyrimidine derivatives incorporated with carbohydrazide, amino, oxadiazol and other moieties also possess potential antioxidant activities ${ }^{[49]}$.

Quiroga et al. ${ }^{[50]}$ synthesized a new compound of 5-aryl4-oxo-3,4,5,8-tetrahydropyrido[2,3-d] pyrimidine-7carboxylic acids and conduct their antioxidant activity by DPPH radical scavenging method. Compounds $6 \mathrm{a}$ and $6 \mathrm{~b}$ (fig. 7) showed good antioxidant activity compared to standard drugs ${ }^{[00]}$.

Mondal et al. ${ }^{[51]}$ synthesized a series of 1-(2-mercapto6-(substituted phenyl)pyrimidine-4-yl)-3-(2-subsituted phenylimino)indoline-2-one and 1-(2-amino6-(substituted phenyl)pyrimidine-4-yl)-3-(2subsitutedphenylimino)indolin-2-ones from different substituted chalconised indole-2,3-diones. Compounds 7a2, 7a3, 7b2, 7b3, 7a6, and 7b6 (fig. 8) show more promising antioxidant activity due to the substitution of the Sulfhydryl (SH) and $\mathrm{NH}_{2}$ groups at the second position of the pyrimidine ring ${ }^{[51]}$.

Gressler et al. ${ }^{[52]}$ synthesized 4-trifluoromethyl2-(5-aryl-3-styryl-1H-pyrazol-1yl)-pyrimidine derivatives. These molecules were screened for their in vitro antioxidant activity using the DPPHwhich measures the hydrogen-donating capacity of the molecules and Horseradish Peroxidase (HRP)/luminol/ $\mathrm{H}_{2} \mathrm{O}_{2}$ chemiluminescence assay method based on the light emission produced by a chemical reaction. When $\mathrm{SH}$ group is present at $\mathrm{R}^{3}$ position, compound 8 a shows potent antioxidant (fig. 9a) ${ }^{[52]}$.

Kumar et al.$^{[33]}$ synthesized a novel series of 4,6-bisarylpyrimidin-2-amine derivative. The synthesized compounds, when evaluated for their antioxidant activity by nitric oxide and hydrogen peroxide free radical scavenging method using ascorbic acid as a standard drug, compound and compound $8 \mathrm{~b} 4$ (fig. 9b) show potent antioxidant activity as compare with the standard drug due to the presence of $-\mathrm{Cl}$ and $-\mathrm{Br}$ as the electron withdrawing group at positions $\mathrm{R}_{1}$ and $\mathrm{R}_{2}$. Compound $8 \mathrm{~b} 4$ was evaluated using nitric oxide free radical scavenging method and by hydrogen peroxide free radical scavenging method. $\mathrm{IC}_{50}$ values of the compound were are 0.019 and $0.020 \mathrm{~mol} / \mathrm{l}$ respectively ${ }^{[53]}$.

Mohana et al. ${ }^{[54]}$ reported novel series of pyrimidine derivatives which were evaluated for antioxidant activity by DPPH method. The structural analysis of all these molecules was done on the basis of Fourier transform infrared spectroscopy, Proton Nuclear Magnetic Resonance ( $\left.{ }^{1} \mathrm{H}-\mathrm{NMR}\right)$ and mass spectral 
<smiles>COc1cc(-c2nc(S)[nH]c(=O)c2C#N)cc(OC)c1OC</smiles>

$4 a$<smiles>COc1cccc(-c2nc(NN)n(C)c(=O)c2C#N)c1</smiles>

$4 b$

Fig. 5: Compounds 4a and 4b<smiles>C=C(Cc1c(N)nc2n(c1=O)C(=O)CS2)NN</smiles>

$5 a$<smiles>Nc1nc2n(c(=O)c1Cc1n[nH]c(=S)o1)C(=O)CS2</smiles>

Fig. 6: Hydrazine and oxadiazole containing thiazolo[3,2-a]pyrimidine derivatives, 5a and $5 b$<smiles>COc1ccc(C2C=C(C(=O)O)Nc3nc(SC)n(C)c(=O)c32)cc1</smiles>

$6 a$<smiles>COc1nc2c(c(=O)n1C)C(c1ccc(F)cc1)C=C(C(=O)O)N2</smiles>

$6 b$

Fig. 7: Compounds 6a and 6b

data. All the compounds showed DPPH radical scavenging activity, whereas, compounds $9 \mathrm{a}, 9 \mathrm{~b}$ and $9 \mathrm{c}$ (fig. 10) exhibited best radical scavengers due to presence of electron donating methoxy group at different position (ortho, meta and para) ${ }^{[54]}$.

Panda et $a l .{ }^{[55]}$ synthesized a novel series of indolylpyrimidine derivatives and all the synthesized molecules were screened for antioxidant activity using DPPH radical scavenging method. Compounds 10a, 10b, 10c, 10d, 10e, 10f and 10g (fig. 11) have exhibited good antioxidant activity which is comparable with that of standard drug, ascorbic acid ${ }^{[55]}$. Table 1 compares these pyrimidine derivatives based on their antioxidant activity.

\section{DRUG CANDIDATES UNDER CLINICAL TRIAL}

The reactive oxygen project team of Pharmacia and Upjohn has identified series of novel pyrrolo[2,3-d] pyrimidine derivatives to be orally active antioxidants and inhibitor of lipid peroxidation which may be used in myocardial infarction, Parkinson's disease, Alzheimer's 


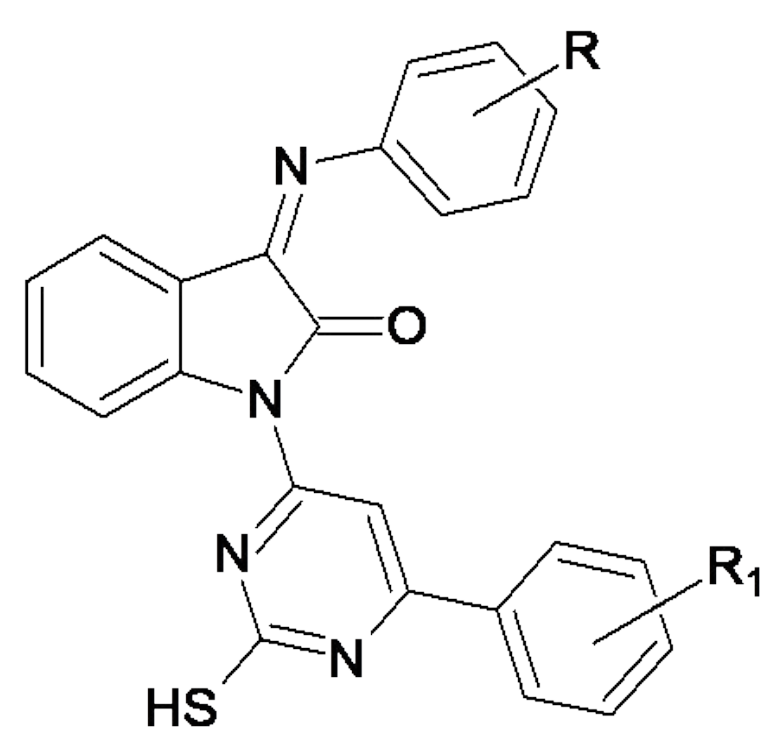

(7a1-7a3) - (7b1-7b3)

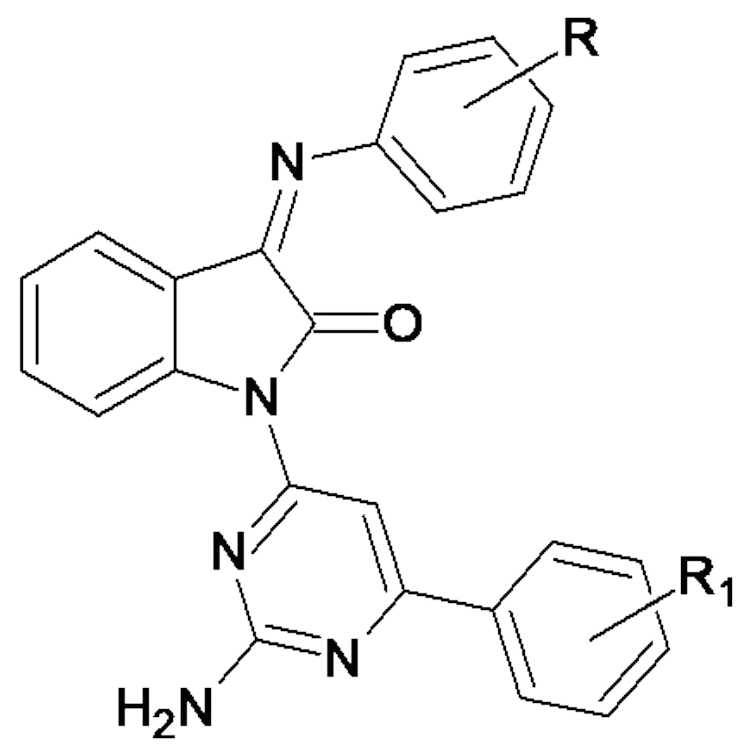

$(7 a 4-7 a 6)-(7 b 4-7 b 6)$

\begin{tabular}{|c|c|c|c|}
\hline $\mathrm{R}$ & $\mathrm{Cl}$ & $\mathrm{NO}_{2}$ & \\
\hline $\mathrm{R}_{1}$ & $\mathrm{NO}_{2}$ & $\mathrm{OH}$ & $\mathrm{OCH}_{3}$ \\
\hline
\end{tabular}

Fig. 8: Mercapto-pyrimidine and amino-pyrimidine derivatives of indoline-2-one<smiles>[R]C=CC1=NN(c2nc([R3])cc(C(F)(F)F)n2)C([R])C1</smiles><smiles>[R]c1ccc(-c2cc(-c3ccc([R2])cc3)nc(N)n2)cc1</smiles>

\begin{tabular}{|c|c|c|}
\hline $\mathrm{R}_{1}$ & $\mathrm{R}_{2}$ & $\mathrm{R}_{3}$ \\
\hline $2-\mathrm{CH}_{3} \mathrm{C}_{6} \mathrm{H}_{4}$ & $2-\mathrm{CH}_{3} \mathrm{C}_{6} \mathrm{H}_{4}$ & $\mathrm{SH}$ \\
\hline
\end{tabular}

(a)

\begin{tabular}{|l|l|l|}
\hline $\mathrm{R}_{1}$ & $\mathrm{Cl}$ & $\mathrm{Cl}$ \\
\hline $\mathrm{R}_{2}$ & $\mathrm{Cl}$ & $\mathrm{Br}$ \\
\hline
\end{tabular}

(b)

Fig. 9: (a) Compound 8a: 2-(4,5-Dihydro-1-H-pyrazol-1-yl)-pyrimidine and (b) Compounds 8b1-8b4

Disease, multiple sclerosis, amyotrophic lateral sclerosis and asthma. The latest in this series 1-[(2,4-di1-pyrroldinyl-9H-pyrimido[4,5-b]indol-9-yl)-acetyl] pyrrolidine monohydrochloride (PNU-142731A), which has shown promising antioxidant activity orally and is currently undergoing phase I clinical trials ${ }^{[56]}$. 


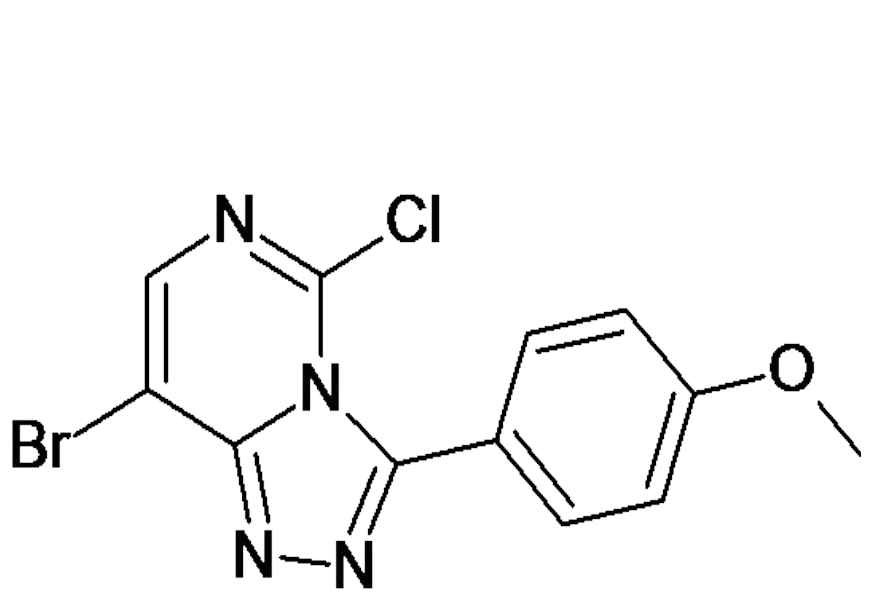

$9 a$

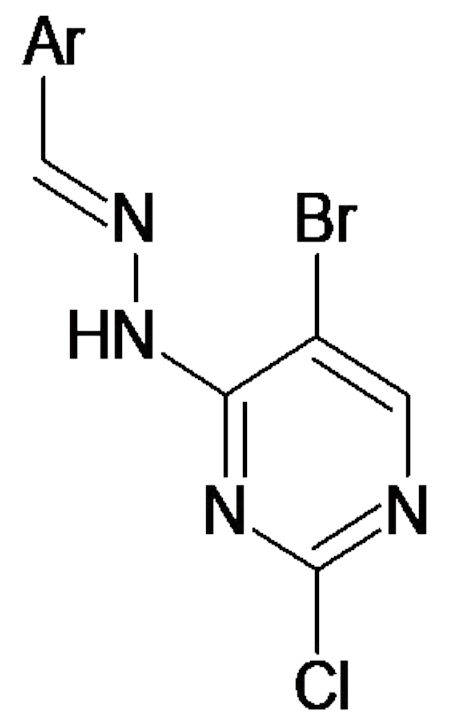

$9 b, 9 c$

\begin{tabular}{|l|c|}
\hline & $\mathrm{Ar}$ \\
\hline $9 \mathrm{~b}$ & 1-methoxy-3-methylbenzene \\
\hline 9c & 2,4-dimethoxy-1-methylbenzene \\
\hline
\end{tabular}

Fig. 10: Compounds 9a, 9b and 9c<smiles>[R]c1ccc(-c2cc(-c3c[nH]c4ccccc34)nc(O)n2)cc1</smiles>

$10(a-c)$<smiles>[R]c1ccc(-c2cc(-c3c[nH]c4ccccc34)nc(N)n2)cc1</smiles>

$10(f-g)$<smiles>[R]c1ccc(-c2cc(-c3c[nH]c4ccccc34)nc(S)n2)cc1</smiles>

\begin{tabular}{|c|c|c|c|c|c|c|c|}
\hline & $10 a$ & $10 b$ & $10 c$ & $10 d$ & $10 e$ & $10 f$ & $10 g$ \\
\hline $\mathrm{R}$ & $\mathrm{NH}_{2}$ & $\mathrm{~F}$ & $\mathrm{OCH}_{3}$ & $\mathrm{NH}_{2}$ & $\mathrm{OCH}_{3}$ & $\mathrm{OH}$ & $\mathrm{OCH}_{3}$ \\
\hline
\end{tabular}

$10(d-e)$

Fig. 11: Compounds 10 (a-g)

In recent studies it has been found that excess of tyrosine kinase Mitogen-Activated Protein Kinase (MEK) 1 and MEK2 leads to tumour. On this basis orally active kinase inhibitors like trametinib and ibrutinib (fig. 12) has been approved by Food and Drug Administration (FDA) to be used as antitumor 
TABLE 1: COMPARATIVE ANTIOXIDANT ACTIVITY OF SYNTHETIC PYRIMIDINE DERIVATIVES

\begin{tabular}{|c|c|c|c|}
\hline S. No & Lead compounds as good antioxidants & Evaluation methods & $\begin{array}{c}\text { Antioxidant } \\
\text { activity }\end{array}$ \\
\hline 1 & Pyrimidine-azitidinone analogues (1a1,1a2,1a3) & $\mathrm{DPPH}, \mathrm{NO}$ and $\mathrm{H}_{2} \mathrm{O}_{2}$ & Good \\
\hline 2 & $\begin{array}{l}\text { Benzofuran-Gathered C-2,4,6-substituted pyrimidine } \\
\text { derivatives conjugated by sulfonyl chlorides }(1 \mathrm{~b} 1,1 \mathrm{~b} 2)\end{array}$ & $\begin{array}{l}\text { DPPH, DMPD and ferric ion reducing } \\
\text { power assay }\end{array}$ & Maximum \\
\hline 3 & Chromenopyrimidinethiones $(2 \mathrm{a})$ & DPPH and ABTS assay & Most potent \\
\hline 4 & $\begin{array}{c}1,3,4 \text {-oxadiazole tagged thieno[2,3- d]pyrimidine } \\
\text { derivatives }(2 \mathrm{~b}, 2 \mathrm{c}, 2 \mathrm{~d}, 2 \mathrm{e})\end{array}$ & DPPH, $\mathrm{NO}$ and $\mathrm{H}_{2} \mathrm{O}_{2}$ & Good \\
\hline 5 & $\begin{array}{c}\text { Tetrahydroimidazo[ }[1,2-a] \text { pyrimidine } \\
\text { derivatives }(3 a, 3 b)\end{array}$ & DPPH & Excellent \\
\hline 6 & $\begin{array}{l}\text { 4-(furan-2-yl)-6-methyl-2-thioxo-1,2,3,4- } \\
\text { tetrahydropyrimidine 5-carboxylate ester (3c) }\end{array}$ & DPPH, $\mathrm{H}_{2} \mathrm{O}_{2}$ and reducing power assay & Most potent \\
\hline 7 & Triazole fused pyrimidine derivatives $(4 a, 4 b)$ & $\begin{array}{l}\mathrm{H}_{2} \mathrm{O}_{2} \text {, Lipid peroxidation inhibitory } \\
\text { activity }\end{array}$ & Most potent \\
\hline 8 & $\begin{array}{l}\text { Thiazolopyrimidines, Pyrrolothiazolopyrimidines and } \\
\text { Triazolopyrrolothiazolopyrimidines derivatives }(5 a, 5 b)\end{array}$ & $\begin{array}{l}\text { ABTS, erythrocyte hemolysis and } \\
\text { bleomycin dependent DNA damage }\end{array}$ & Potent \\
\hline 9 & $\begin{array}{c}\text { 5-aryl-4-oxo-3,4,5,8-tetrahydropyrido[2,3-d]pyrimidine-7- } \\
\text { carboxylic acids }(6 \mathrm{a}, 6 \mathrm{~b})\end{array}$ & DPPH, ORAC & Good \\
\hline 10 & $\begin{array}{l}\text { Mercapto-pyrimidine and amino-pyrimidine derivatives of } \\
\text { indoline-2-one }(7 \mathrm{a} 2,7 \mathrm{a} 3,7 \mathrm{~b} 2,7 \mathrm{~b} 3,7 \mathrm{a} 4 \text { and } 7 \mathrm{~b} 4)\end{array}$ & DPPH & Promising \\
\hline 11 & $\begin{array}{c}\text { 4-trifluoromethyl-2-(5-aryl-3-styryl-1H-pyrazol-1yl)- } \\
\text { pyrimidine derivatives }(8 \mathrm{a})\end{array}$ & $\begin{array}{l}\mathrm{DPPH} \text { and } \mathrm{HRP} / \text { luminol } / \mathrm{H}_{2} \mathrm{O}_{2} / \\
\text { chemiluminescence assay }\end{array}$ & Potent \\
\hline 12 & 4,6-bisaryl-pyrimidin-2-amine derivative (8b1-8b4) & $\mathrm{NO}$ and $\mathrm{H}_{2} \mathrm{O}_{2}$ method & Potent \\
\hline 13 & New series of pyrimidine derivatives $(9 a, 9 b, 9 c)$ & DPPH & Best \\
\hline 14 & Indolyl-pyrimidine derivatives (10a-10g) & DPPH & Good \\
\hline
\end{tabular}<smiles>CC(=O)Nc1cccc(-n2c(=O)n(C3CC3)c(=O)c3c(Nc4ccc(I)cc4F)n(C)c(=O)c(C)c32)c1</smiles>

Trametinib

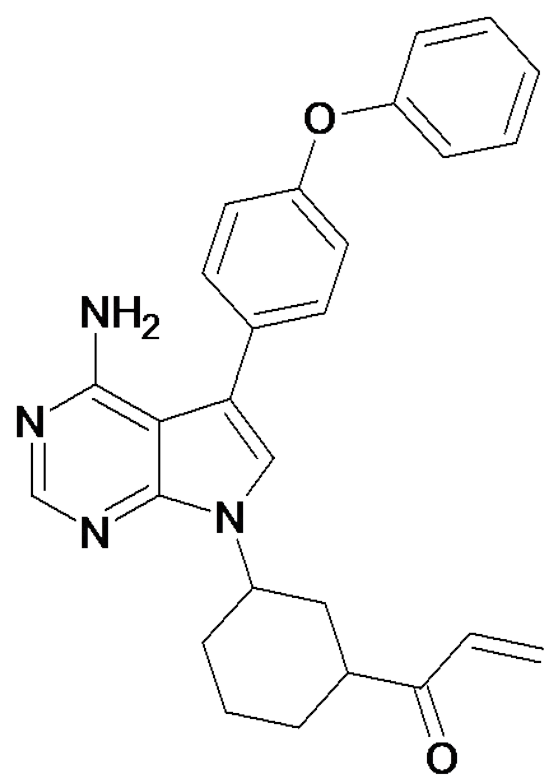

Ibrutinib

Fig. 12: Drug candidates under clinical trials

in patients with inoperable or metastatic melanoma in early 2012. Trametinib is now used in combination with dabrafenib. Ibrutinib has undergone extensive set of clinical trials in 2013 and FDA granted approval for use of this drug in specific lymphoma. Trametinib and ibrutinib are available in the market by trade name MEKINIST $^{\circledR}$ and IMBRUVICA ${ }^{\circledR[57]}$.

\section{CONCLUSION}

The antioxidants have the ability to trap as well as scavenge ROS and may be of great value in preventing the onset and propagation of different diseases. Pyrimidine is a unique molecule and has a long and distinguished history extending from 
the days of discovery as important constituents of nucleic acid to their wide clinical applications including in cancer. Various pyrimidine derivatives have shown promising antioxidant activity. Majority of compounds shown significant radical scavenging properties due to the presence of electron donating substituent on the pyrimidine nucleus which enhances the radical scavenging activity and serves to improve the potency. The antioxidants bearing pyrimidine nucleus are not able to enter in the lipid moiety of lowdensity lipoprotein, hence these types of compounds portray very low penetration power, in turn reducing effectivity. Substitution with electron donating groups like $\mathrm{Br}, \mathrm{NO}_{2}, \mathrm{CF}_{3}$ and $\mathrm{Cl}$ on the pyrimidine nucleus may increase the penetration of molecules into the lipid membrane which increases the antioxidant activity by combining with the ROS, which is generated in different disease conditions. However, the electron withdrawing substituent may decrease the antioxidant activity. In short, high antioxidant activity can be correlated with low electron density of ring system owing to good antioxidant activity of substituted pyrimidine.

\section{Conflict of interests:}

The authors declared no conflicts of interest.

\section{REFERENCES}

1. Taylor AP, Robinson RP, Fobian YM, Blakemore DC, Jones LH, Fadeyi O. Modern advances in heterocyclic chemistry in drug discovery. Org Biomol Chem 2016;14(28):6611-37.

2. Kiuru P, Kauhaluoma JY. Pyridine and its derivatives. In: Majumdar KC, Chattopadhyay SK, editor. Heterocycles in natural product synthesis. John Wiley and Sons; 2011. p. 26797.

3. Bolzani VD, Gunatilaka AL, Kingston DG. Bioactive and other piperidine alkaloids from Cassia leptophylla. Tetrahedron 1995;51(21):5929-34.

4. Merugu R, Garimella S, Balla D, Sambaru K. Synthesis and biological activities of pyrimidines: A review. Int J Pharm Tech Res 2015;8(6):88-93.

5. Garrett R, Grisham C. Biochemistry. 4th ed. Boston: Brooks Cole; 2008.

6. Kumar S, Narasimhan B. Therapeutic potential of heterocyclic pyrimidine scaffolds. Chem Cent J 2018;12(1):1-29.

7. Yousif MN, El-Sayed WA, Abbas HA, Awad HM, Yousif NM. Anticancer activity of new substituted pyrimidines, their thioglycosides and thiazolopyrimidine derivatives. J Appl Pharm Sci 2017;7(11):21-32.

8. Hafez HN, Hussein HA, El-Gazzar AR. Synthesis of substituted thieno [2, 3-d] pyrimidine-2, 4-dithiones and their S-glycoside analogues as potential antiviral and antibacterial agents. Eur J Med Chem 2010;45(9):4026-34.

9. Stefani HA, Oliveira CB, Almeida RB, Pereira CM, Braga $\mathrm{RC}$, Cella R, et al. Dihydropyrimidin- $(2 \mathrm{H})$-ones obtained by ultrasound irradiation: A new class of potential antioxidant agents. Eur J Med Chem 2006;41(4):513-8.

10. Kikuchi H, Yamamoto K, Horoiwa S, Hirai S, Kasahara
$\mathrm{R}$, Hariguchi $\mathrm{N}$, et al. Exploration of a new type of antimalarial compounds based on febrifugine. J Med Chem 2006;49(15):4698-706.

11. Singh B, Maheshwari A, Dak G, Sharma K, Talesara GL. Studies of antimicrobial activities of some 4-thiazolidinone fused pyrimidines, [1,5]-benzodiazepines and their oxygen substituted hydroxylamine derivatives. Indian J Pharm Sci 2010;72(5):607.

12. El-Bahaie S, Kadry AM, Assy MG, Ibrahim YA. Synthesis and biological activity of some new pyrimidine and thienopyrimidine derivatives. Die Pharmazie 1988;43(8):5378.

13. Bhuiyan MD, Rahman K, Mizanur M, Hossain MK, Rahim A, Hossain I, et al. Synthesis and antimicrobial evaluation of some new thienopyrimidine derivatives. Acta Pharma 2006;56(4):441-50.

14. Prasad MR, Prashanth J, Shilpa K, Kishore DP. Synthesis and antibacterial activity of some novel triazolothienopyrimidines. Chem Pharm Bull 2007;55(4):557-60.

15. Aly HM, Saleh NM, Elhady HA. Design and synthesis of some new thiophene, thienopyrimidine and thienothiadiazine derivatives of antipyrine as potential antimicrobial agents. Eur J Med Chem 2011;46(9):4566-72.

16. Maddila S, Gorle S, Seshadri N, Lavanya P, Jonnalagadda SB. Synthesis, antibacterial and antifungal activity of novel benzothiazole pyrimidine derivatives. Arab J Chem 2016;9(5):681-7.

17. Alagarsamy V, Meena S, Ramseshu KV, Solomon VR, Thirumurugan K, Dhanabal K, et al. Synthesis, analgesic, antiinflammatory, ulcerogenic index and antibacterial activities of novel 2-methylthio-3-substituted-5,6,7,8-tetrahydrobenzo (b) thieno [2,3-d] pyrimidin-4 (3H)-ones. Eur J Med Chem 2006;41(11):1293-300.

18. Russell RK, Press JB, Rampulla RA, McNally JJ, Falotico R, Keiser JA, et al. Thiophene systems. 9. Thienopyrimidinedione derivatives as potential antihypertensive agents. J Med Chem 1988;31(9):1786-93.

19. Ohkawa H, Ohishi N, Yagi K. Assay for lipid peroxides in animal tissues by thiobarbituric acid reaction. Anal Biochem 1979;95(2):351-8.

20. McCord JM. The evolution of free radicals and oxidative stress. Am J Med 2000;108(8):652-9.

21. Kotaiah Y, Harikrishna N, Nagaraju K, Rao CV. Synthesis and antioxidant activity of 1,3,4-oxadiazole tagged thieno [2,3-d] pyrimidine derivatives. Eur J Med Chem 2012;58:340-5.

22. Satyanarayana U, Chakrapani U. Biochemistry. 5th ed. India: Elsevier RELX India Ltd and Books and Allied Pvt. Ltd; 2017.

23. Barry H. Antioxidant effects a basis for drug selection. Drugs 1991;42(2):569-605.

24. Rao AL, Bharani M, Pallavi V. Role of antioxidants and free radicals in health and disease. Adv Pharmacol Toxicol 2006;7(1):29-38.

25. Rababah TM, Hettiarachchy NS, Horax R. Total phenolics and antioxidant activities of fenugreek, green tea, black tea, grape seed, ginger, rosemary, gotu kola and ginkgo extracts, vitamin $\mathrm{E}$ and tert-butylhydroquinone. J Agri Food Chem 2004;52(16):5183-6.

26. Lobo V, Patil A, Phatak A, Chandra N. Free radicals, antioxidants and functional foods: Impact on human health. Pharmacogn Rev 2010;4(8):118.

27. Salem MS, Farhat M, Errayes AO, Madkour HM. Antioxidant activity of novel fused heterocyclic compounds derived from tetrahydropyrimidine derivative. Chem Pharm Bull 
2015;63(11):866-72.

28. Ashoori M, Saedisomeolia A. Riboflavin (vitamin B2) and oxidative stress: A review. Br J Nutr 2014;111(11):1985-91.

29. Greb A, Bitsch R. Comparative bioavailability of various thiamine derivatives after oral administration. Int $\mathrm{J}$ Clin Pharmacol Ther 1998;36(4):216-21.

30. Kedare SB, Singh RP. Genesis and development of DPPH method of antioxidant assay. J Food Sci Technol 2011;48(4):412-22.

31. Marcocci L, Maguire JJ, Droylefaix MT, Packer L. The nitric oxide-scavenging properties of Ginkgo biloba extract EGb 761. Biochem Biophys Res Commun 1994;201(2):748-55.

32. Balakrishnan N, Panda AB, Raj NR, Shrivastava A, Prathani R. The evaluation of nitric oxide scavenging activity of Acalypha indica Linn root. Asian J Res Chem 2009;2(2):148-50.

33. Benzie IF, Strain JJ. Ferric reducing/antioxidant power assay: Direct measure of total antioxidant activity of biological fluids and modified version for simultaneous measurement of total antioxidant power and ascorbic acid concentration. Methods Enzymol 1999;299:15-27.

34. Ueda JI, Saito N, Shimazu Y, Ozawa T. A comparison of scavenging abilities of antioxidants against hydroxyl radicals. Arch Biochem Biophys 1996;333(2):377-84.

35. Babu BH, Shylesh BS, Padikkala J. Antioxidant and hepatoprotective effect of Acanthus ilicifolius. Fitoterapia 2001;72(3):272-7.

36. Ghiselli A, Serafini M, Maiani G, Azzini E, Ferro-Luzzi A. A fluorescence-based method for measuring total plasma antioxidant capability. Free Radic Biol Med 1995;18(1):29-36.

37. Pisoschi AM, Negulescu GP. Methods for total antioxidant activity determination: A review. Biochem Anal Biochem 2011;1(1):106.

38. Litescu SC, Eremia SA, Tache A, Vasilescu I, Radu GL. The use of oxygen radical absorbance capacity (ORAC) and Trolox equivalent antioxidant capacity (TEAC) assays in the assessment of beverages' antioxidant properties. InProcessing and impact on antioxidants in beverages 2014;245-51.

39. Owens CW, Belcher RV. A colorimetric micro-method for the determination of glutathione. Biochem J 1965;94(3):705-11.

40. Benzie IF, Strain JJ. The ferric reducing ability of plasma (FRAP) as a measure of "antioxidant power": The FRAP assay. Anal Biochem 1996;239(1):70-6.

41. Ou B, Huang D, Hampsch-Woodill M, Flanagan JA, Deemer EK. Analysis of antioxidant activities of common vegetables employing oxygen radical absorbance capacity (ORAC) and ferric reducing antioxidant power (FRAP) assays: A comparative study. J Agri Food Chem 2002;50(11):3122-8.

42. Moniruzzaman M, Khalil MI, Sulaiman SA, Gan SH. Advances in the analytical methods for determining the antioxidant properties of honey: A review. African J Tradit Complement Alternat Med 2012;9(1):36-42.

43. ChandrashekaraiahM,LingappaM,GowdaVDC,Bhadregowda DG. Synthesis of some new pyrimidine-azitidinone analogues and their antioxidant, in vitro antimicrobial and antitubercular activities. J Chem 2014;2014:1-9.

44. Rangaswamy J, Kumar HV, Harini ST, Naik N. Synthesis of
Novel Benzofuran-Gathered C-2,4,6-substituted Pyrimidine Derivatives Conjugated by Sulfonyl Chlorides: Orally bioavailable, selective, effective antioxidants and antimicrobials drug candidates. J Heterocycl Chem 2015;52(5):1349-60.

45. Khoobi M, Ramazani A, Hojjati Z, Shakeri R, Khoshneviszadeh M, Ardestani SK, et al. Synthesis of Novel 4 H-Chromenes Containing a Pyrimidine-2-Thione Function in the Presence of $\mathrm{Fe}_{3} \mathrm{O}_{4}$ Magnetic Nanoparticles and Study of Their Antioxidant Activity. Phosphorus Sulfur Silicon Relat Elem 2014;189(10):1586-95.

46. Rani J, Saini M, Kumar S, Verma PK. Design, synthesis and biological potentials of novel tetrahydroimidazo [1,2-a] pyrimidine derivatives. Chem Cent J 2017;11(1):1-16.

47. Mansouri M, Movahedian A, Rostami M, Fassihi A. Synthesis and antioxidant evaluation of 4-(furan-2-yl)-6-methyl-2thioxo-1,2,3,4-tetrahydropyrimidine-5-carboxylate esters. Res Pharm Sci 2012;7(4):257.

48. Bhalgat CM, Ali MI, Ramesh B, Ramu G. Novel pyrimidine and its triazole fused derivatives: Synthesis and investigation of antioxidant and anti-inflammatory activity. Arab J Chem 2014;7(6):986-93.

49. Abu-Hashem AA, Youssef MM, Hussein HA. Synthesis, antioxidant, antituomer activities of some new thiazolopyrimidines, pyrrolothiazolopyrimidines and triazolopyrrolothiazolopyrimidines derivatives. J Chin Chem Soc 2011;58(1):41-8.

50. Quiroga J, Romo PE, Ortiz A, Isaza JH, Insuasty B, Abonia $\mathrm{R}$, et al. Synthesis, structures, electrochemical studies and antioxidant activity of 5-aryl-4-oxo-3,4,5,8-tetrahydropyrido [2,3-d] pyrimidine-7-carboxylic acids. J Mol Struct 2016;1120:294-301.

51. Mondal P, Jana S, Kanthal LK. Synthesis of novel mercaptopyrimidine and amino-pyrimidine derivatives of indoline-2one as potential antioxidant and antibacterial agents. Pharm Res 2010;3:17-26.

52. Gressler V, Moura S, Flores AF, Flores DC, Colepicolo P, Pinto E. Antioxidant and antimicrobial properties of 2-(4,5-dihydro1H-pyrazol-1-yl)-pyrimidine and 1-carboxamidino-1Hpyrazole derivatives. J Braz Chem Soc 2010;21:1477-83.

53. Kumar SM, Pavani M, Bhalgat CM, Deepthi R, Mounika A, Mudshinge SR. In vitro antioxidant studies of 4,6-bis aryl-pyrimidin-2-amine derivatives. Int $\mathrm{J}$ Pharm Bio Sci 2009;2:1568-70.

54. Mohana KN, Kumar BN, Mallesha L. Synthesis and biological activity of some pyrimidine derivatives. Drug Invent Today 2013;5(3):216-22.

55. Panda SS, Chowdary PV. Synthesis of novel indolyl-pyrimidine antiinflammatory, antioxidant and antibacterial agents. Indian J Pharm Sci 2008;70(2):208.

56. Easter JA. Synthesis Of Isotopically Labelled 1-[(2,4-DI1-Pyrollidinyl-9 H-Pyrimido [4,5-B] indol-9-yl)-acetyl) pyrollidine monohydrochloride, PNU-142731A, An Orally Active Antiasthamatic Agent. In: Isotope Production And Applications In The 21st Century, World Scientific; 2000. p. 345-6.

57. Lednicer D. Antineoplastic Drugs: Organic Syntheses. John Wiley and Sons; 2015. 